\title{
MUNICIPAL DEBT AND MARGINAL TAX RATES: IS THERE A TAX PREMIUM IN ASSET PRICES?
}

\author{
Francis A. Longstaff \\ Working Paper 14687 \\ http://www.nber.org/papers/w14687
NATIONAL BUREAU OF ECONOMIC RESEARCH 1050 Massachusetts Avenue Cambridge, MA 02138
January 2009

UCLA Anderson School and NBER. I am very grateful for helpful discussions with Hanno Lustig, Douglas Montague, Eric Neis, Mike Rierson, Derek Schaeffer, and Joel Silva. All errors are my responsibility. The views expressed herein are those of the author(s) and do not necessarily reflect the views of the National Bureau of Economic Research.

(C) 2009 by Francis A. Longstaff. All rights reserved. Short sections of text, not to exceed two paragraphs, may be quoted without explicit permission provided that full credit, including $\odot$ notice, is given to the source. 
Municipal Debt and Marginal Tax Rates: I̦s there a Tax Premium in Asset Prices?

Francis A. Longstaff

NBER Working Paper No. 14687

January 2009

JEL No. G12,H2

\begin{abstract}
$\underline{\text { ABSTRACT }}$
We study the marginal tax rate incorporated into short-term tax-exempt municipal rates using a unique new data set from the municipal swap market. By applying an affine term-structure framework, we are able to identify both the marginal tax rate and the credit/liquidity spread in one-week tax-exempt rates. Furthermore, we obtain maximum likelihood estimates of the risk premia associated with these variables. The average marginal tax rate during the sample period is 41.6 percent. We find that the marginal tax rate is significantly positively related to returns in the stock and bond markets. The risk premium associated with the marginal tax rate is negative, consistent with the strong contracyclical nature of aftertax fixed-income cash flows which increase in bad states of the economy as personal income and the effective marginal tax rates applied to those cash flows decline.
\end{abstract}

Francis A. Longstaff

UCLA

Anderson Graduate School of Management

110 Westwood Plaza, Box 951481

Los Angeles, CA 90095-1481

and NBER

francis.longstaff@anderson.ucla.edu 


\section{INTRODUCTION}

One of the most fundamental issues in Finance is the question of how taxes affect security values. This important topic has been the focus of an extensive literature which now dates back nearly a century. Despite the many important contributions in this area, however, there is still much about the effects of taxation on investment values that is not yet fully understood.

The challenge is particularly evident in studying municipal debt markets. Many researchers have documented that the ratio of municipal bond yields to Treasury or corporate bond yields appears to imply marginal tax rates that are much smaller than would be expected given Federal income tax rates. Key papers discussing this munibond puzzle include Trzcinka (1982), Livingston (1982), Arak and Gentner (1983), Stock and Schrems (1984), Ang, Peterson, and Peterson (1985), Buser and Hess (1986), Kochin and Parks (1988), and Green and Oedegaard (1997). A number of papers consider whether the puzzle can be explained by municipal credit risk, including Kidwell and Trzcinka (1982), Skelton (1983), Chalmers (1998), and Neis (2006). In an important paper, Green (1993) develops a simple model that takes into account the asymmetries between the taxation of capital gains and losses as well as the treatment of coupon income and shows that the resulting effect of these tax asymmetries may help explain the muni-bond puzzle.

This paper presents a new and fundamentally different approach to estimating the marginal tax rate $\tau_{t}$ incorporated into tax-exempt municipal debt rates. In doing this, we take advantage of an extensive new data set that includes both the yields of oneweek tax-exempt municipal debt as well as the term structure of rates for municipal swaps exchanging this tax-exempt yield for a percentage of Libor. Using this data, we estimate an affine term structure model of the municipal swap curve via maximum likelihood and obtain estimates of both the marginal tax rate and the credit/liquidity spread embedded in municipal yields.

This new approach has a number of important advantages. First, by estimating the marginal tax rate from one-week municipal yields, our results are free of the types of tax-asymmetry or tax-trading complications that Green (1993), Constantinides and Ingersoll (1982), and others show may affect yields on longer-term municipal bonds. Second, this approach allows us to estimate the market risk premia incorporated into the term structure as compensation to investors for bearing the risk of time variation in the marginal tax rate. Thus, we can directly evaluate whether there is a tax premium embedded in asset prices stemming from the progressive nature of income taxation in the U.S. Third, our approach allows us to study directly how changes in marginal tax rates are related to financial and macroeconomic shocks. 
The empirical results are very striking. We find that the average marginal tax rate during the 2001-2008 sample period is 41.6 percent. This value is slightly higher than the maximum Federal income tax rate of 39.1 percent during 2001, 38.6 percent during 2002 , and 35.0 percent during the remainder of the sample period. Thus, these results are consistent with a scenario in which the marginal tax reflects both Federal and state income taxes. The estimated marginal tax rate, however, varies substantially through time and ranges from roughly 31 to 49 percent during the sample period. These estimates of the marginal tax rate are also consistent with the higher marginal rates identified by Ang, Bhansali, and Xing (2008) in an important recent paper studying the cross-sectional pricing of discount municipal bonds.

The estimated values of the marginal tax rate are also significantly larger than those obtained by a naive comparison of the short-term tax-exempt rate to the corresponding fully-taxable riskless rate. Intuitively, the reason for this is that there is a substantial credit/liquidity spread incorporated into short-term tax-exempt municipal yields. We find that the average value of this spread during the sample period is 106 basis points. The estimated spread, however, increased dramatically during the early stages of the subprime credit crisis as monoline municipal bond insurers suffered major credit-related losses and auction failures in the short-term auction-rate-security markets became widespread.

To explore how the marginal tax rate evolves over time, we regress changes in the marginal tax rate on a number of variables proxying for changes in investors' personal income. We find that the marginal tax rate is significantly and positively related to returns on the S\&P 500 and on U.S. Treasury bonds. In contrast, the marginal tax rate is not significantly related to broader measures of aggregate personal income growth. These results provide intriguing insights into the nature of the marginal investor in the municipal bond markets.

One of the most surprising empirical results is that the market risk premium for the marginal tax rate is negative in sign. In particular, the long-run expected marginal tax rate is 41.7 percent which is substantially higher than the long-run forward marginal tax rate of 29.4 percent. This means that the present value of the product of a fixed cash flow and $1-\tau_{t}$ (which is just the aftertax value of that cash flow) can be significantly larger than its expected value discounted at the riskless rate.

To understand the reason for this negative risk premium, observe that marginal tax rates are very procyclical because of the progressivity of the Federal income tax system. In good states of the economy, personal income increases and investors move into higher marginal tax brackets, while the opposite is true in bad states of the economy. This means that $c\left(1-\tau_{t}\right)$, where $c$ is the coupon on a bond, is actually highly contracyclical. Thus, the risk premium for this cash flow can be negative because of its "negative consumption beta." 
A key implication of these results is that the negative risk premium for the marginal tax rate may help explain a significant portion of the muni-bond puzzle. In particular, our results suggest that the negative risk premium may reduce the spread between longer-term Treasury and tax-exempt municipal yields by 50 basis points or more during the sample period. Thus, these results complement and extend those provided by Green (1993), Chalmers (1998), and others.

Other important recent research on municipal debt markets includes Green and Oedegaard (1997), Downing and Zhang (2004), Nanda and Singh (2004), Green (2007), Green, Hollifield, and Schürhoff (2007a, b), Green, Li, and Schürhoff (2007), and Ang, Bhansali, and Xing (2008). Important papers addressing the impact of taxation on bond prices and trading strategies include Livingston (1979), Constantinides and Ingersoll (1982), Schaefer (1982), Litzenberger and Rolfo (1984), Jordan (1984), Dybvig and Ross (1986), Dammon and Green (1987), Graham (2003), and Dammon, Spatt, and Zhang (2004).

The remainder of the paper is organized as follows. Section 2 provides an introduction to the municipal swap market. Section 3 describes the data used in the study. Section 4 presents the affine model of the term structure of municipal swap rates. Section 5 describes the maximum likelihood estimation of the model. Section 6 presents the empirical results. Section 7 summarizes the results and presents concluding remarks.

\section{THE MUNICIPAL SWAP MARKET}

In this section we provide a brief introduction to the municipal swap market. Since swaps in this market are tied to the Securities Industry and Financial Markets Association Municipal Swap Index (MSI), we first explain how this index is constructed. We then describe the various types of municipal swap contracts available in the overthe-counter financial markets.

\subsection{The Municipal Swap Index}

The MSI is a high-grade market index reflecting the yields on seven-day-resettable tax-exempt variable-rate demand obligations (VRDOs). Thus, the MSI is effectively a one-week tax-exempt rate. The index is produced by Municipal Market Data which maintains an extensive database containing information for more than 15,000 active VRDOs. Municipal Market Data is a subsidiary of Thompson Financial Services. ${ }^{1}$

\footnotetext{
${ }^{1}$ This section is based on the description of the market provided by the Securities Industry and Financial Markets Association (www.sifma.org/capital_markets/swapindex.sht $\mathrm{ml})$.
} 
VRDOs are long-term tax-exempt floating-rate notes issued by municipalities. Typically, the floating rate on the notes is reset at a weekly frequency, although both shorter and longer frequencies occur in the markets. Although the maturities of VRDOs are often 30 to 40 years, they are effectively shorter-term securities since they can be put back or tendered to the investment dealer or remarketing agent on a schedule coinciding with the weekly yield reset.

The remarketing agent, which is often the financial institution that originally issued the VRDO for the municipality, has two ongoing roles. First, the remarketing agent functions as a broker in that if VRDOs are tendered at the weekly yield reset, the remarketing agent attempts to find a buyer for the tendered VRDOs. Second, as part of this process, the remarketing agent sets the weekly yield to whatever level is required for the market to clear the tendered VRDOs (and which may also incorporate market information about market-clearing rates for similar VRDO issues). In this respect, VRDOs have a number of features in common with auction-rate securities which also reset frequently via a market clearing mechanism. Note, however, that the weekly reset for a VRDO is determined by the remarketing agent while the weekly reset for an auction-rate note is determined via a constrained Dutch auction (which may fail in that the maximum allowable yield is below the rate needed to clear the market. ${ }^{2}$ VRDOs are typically issued at par. When they are put back to the remarketing agent, an investor receives par plus accrued interest. Criscuolo and Faloon (2007) estimate that 70 percent of VRDOs are held by money market funds, 15 percent are held by corporations, 7 percent are held by bond funds, and 8 percent are held by trust departments. The VRDO market presents a large and rapidly growing segment of the $\$ 2.6$ trillion municipal debt market. In particular, the Securities Industry and Financial Markets Association reports that $\$ 63.3$ billion of variable-rate municipal bond obligations were issued during 2007 , and that $\$ 94.9$ billion were issued through August of 2008.

There are a number of criteria which a VRDO must satisfy for its yield to be included in the MSI. First, the VRDO must have a weekly reset, effective on Wednesday. Second, the VRDO must not be subject to alternative minimum tax. Third, the VRDO must have an outstanding amount of at least $\$ 10$ million. Fourth, the VRDO must have the highest short-term rating which is VMIG1 by Moody's or A-1+ by Standard and Poor's. Historically, a municipal issuer of VRDOs would need to obtain some sort of credit enhancement (such as a letter of credit from a highly-rated bank) to obtain the highest short-term rating. ${ }^{3}$ Fifth, the VRDO must pay interest

${ }^{2}$ For a discussion of the auction-rate markets, see McConnell and Sarreto (2008) and Sulzberge and Flynn (2008).

${ }^{3}$ For a discussion of the role of credit enhancement in VRDO issuance, see Criscuolo and Faloon (2007). 
on a monthly basis, calculated on an actual/actual basis. Finally, only one quote per obligor per remarketing agent can be included in the MSI. The MSI can include issues from any state. The MSI is calculated weekly on Wednesday and released on Thursday.

The underlying source data for the index comes from Municipal Market Data's Variable Rate Demand Note Network. This network collects market data from over 80 remarketing agents who download daily rate change information to Municipal Market Data's network. The actual number of VRDOs included in the weekly index fluctuates, but is estimated to include roughly 650 issues in any given week.

\subsection{The Municipal Swap Market}

The primary type of municipal swap contract available in the financial markets is the percentage-of-Libor contract. This contract is very similar to a standard floatingfor-floating basis swap contract. Specifically, one counterparty to the municipal swap contract agrees to pay the other the numerical value of the MSI at some frequency, say, monthly. In exchange, the other counterparty commits to pay the first counterparty a fixed percentage $P$ of the numerical value of the Libor rate. Both payments are made relative to a specific notional amount and are accrued on a standard actual/360 daycount convention. For example, if payments are exchanged monthly, the first counterparty would pay the second the average value of the one-week MSI rate during the month times the daycount fraction on the swap notional amount. The second counterparty would pay the first $P$ times the one-month Libor rate set at the beginning of the month times the same daycount fraction on the swap notional.

It is important to stress that the cash flows from both the MSI and Libor legs of a municipal swap contract will typically be fully taxable to the swap counterparties. The tax-exempt status of the interest from the VRDOs included in the MSI does not carry over to financial contracts with cash flows that are tied to the numerical value of the index. Thus, the marginal tax rate enters into the pricing of a muncipal swap only through its effect on the one-week MSI rate. It is this feature that enables us to abstract completely from the types of tax asymmetries that affect the valuation of longer-maturity municipal bonds as described by Green (1993).

In this market, municipal swaps are quoted in terms of the percentage $P$ required to make both legs of the swap have equal value. Intuitively, the reason for the percentage $P$ is easily seen. Since the MSI is a tax-exempt rate, its numerical value will likely be substantially lower that the numerical value of the fully-taxable Libor rate. Thus, the counterparty paying Libor would generally not be willing to pay Libor flat in exchange for the MSI rate. Typically, the market-clearing value of $P$ is significantly lower than 100 percent. Like conventional interest rate swaps, municipal swaps are traded in the OTC markets. Market quotations for municipal swaps with 1-, 2-, 3-, 4-, 5-, 7-, 10-, 12-, 15-, 20-, 25-, and 30-year maturities are currently readily available in the Bloomberg system and from other market data sources. 
A popular alternative type of municipal swap contract is given by combining a percentage-of-Libor contract with a standard fixed-for-floating Libor interest rate swap. To illustrate, imagine that municipal swap market participants are willing to pay 70 percent of Libor to receive the MSI rate over the next 10 years. Furthermore, imagine that swap market participants are also willing to pay Libor to receive a fixed rate of 6 percent over the next 10 years in a standard swap. Then a simple arbitrage argument implies that market participants should be willing to pay a fixed rate of $0.70 \times 0.0600=0.0420$ to receive the MSI rate over the next 10 years. Thus, there is a simple equivalence between percentage-of-Libor swaps and these fixed-for-MSI-rate swaps.

\section{THE DATA}

The data for the study include the one-week tax-exempt MSI rate, market rates for percentage-of-Libor municipal swaps, as well as Treasury, repo, and swap market rates. The different categories of data are described individually below.

\subsection{The Municipal Swap Index Data}

We obtain weekly observations of the one-week tax-exempt MSI rate directly from the Securities Industry and Financial Markets Association website for the period from August 1, 2001 to June 18, 2008; see http://archives.sifma.org/swap data.html. We choose this time period since municipal swap data is only available for this horizon. The time period provides a total of 360 weekly observations. The vast majority of these weekly observations are for Wednesday. ${ }^{4}$ Table 1 provides summary statistics for the data.

\subsection{Treasury Repo Rate Data}

In solving for the marginal tax rate incorporated into the one-week tax-exempt MSI, it will be helpful to have a fully-taxable one-week riskless rate to use as a benchmark. While one-month, three-month, and six-month Treasury bill yield data are readily available in the financial markets, data for shorter maturities are difficult to obtain and are likely to be less reliable. To circumvent this difficulty, we will use the one-week Treasury repo rate as a proxy for the one-week riskless rate. ${ }^{5}$ We obtain midmarket data for the one-week Treasury repo data from the Bloomberg system for the same

\footnotetext{
${ }^{4}$ In a few instances, the MSI is reported for an alternative day of the week such as Thursday.

${ }^{5}$ The empirical results of this study are virtually the same when the one-month Treasury bill rate is used as a proxy for the one-week riskless rate.
} 
dates as the MSI data.

There are a number of justifications for the use of the Treasury repo rate as a proxy for the riskless rate. First, as argued in Longstaff (2000), repo rates reflect the actual cost of capital to government bond dealers for their positions in Treasury bonds. Second, Treasury repo contracts are fully collateralized, or more generally, overcollateralized by the underlying Treasury bonds associated with the transaction. Thus, there is little default risk associated with a short-term government repo contract. Third, as discussed by Duffee (1998) and others, Treasury bill yields display a significant amount of idiosyncratic variation which may not be related to movements in the economic riskless rate. For example, Longstaff (2004) shows that Treasury yields can be affected by flights-to-quality or flights-to-liquidity.
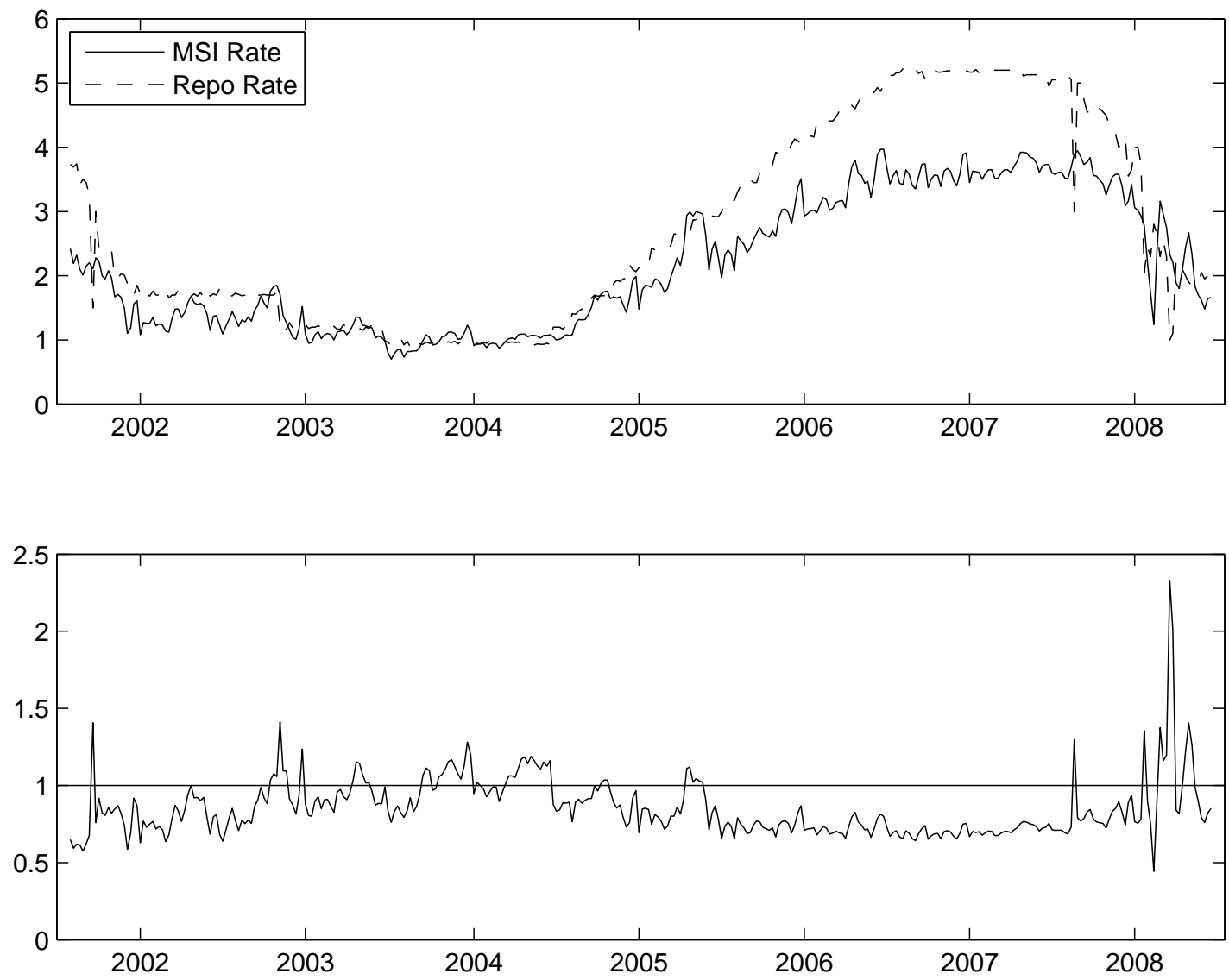

Figure 1. The MSI and Repo Rates. The upper panel plots the MSI rate and the repo rate. The lower panel plots the ratio of the MSI rate to the repo rate. 
Finally, Treasury securities may not actually be default free. In particular, the fiveyear credit default swap premium for the U.S. Treasury has been quoted at levels as high as 24 basis points. ${ }^{6}$

To provide some preliminary perspective on the relation between taxable and taxexempt rates, Figure 1 plots the the MSI and repo rates in the upper panel and the ratio of the MSI rate to the repo rate in the lower panel. As illustrated, the relation between the taxable and tax-exempt rates is fairly complex. On average, the MSI rate is 85.4 percent of the repo rate. At a first glance, this seems to suggest that the average marginal tax rate is only $100-85.4=14.6$ percent. In reality, however, this simplistic measure of the marginal tax rate fails to take into account the credit risk incorporated into the tax-exempt curve. While the MSI rate is based on yields for VRDOs with the highest short-term credit rating, the MSI rate may still reflect the default risk inherent in the municipal bond issuers and/or the financial institutions providing credit enhancement for the VRDOs. Thus, if the MSI rate contains a credit risk spread, the simple ratio of the MSI rate to the repo rate would give a downward biased measure of the marginal tax rate.

In fact, Figure 1 shows that the tax-exempt rate has frequently exceeded the repo rate. For example, the ratio of the tax-exempt MSI rate to the taxable repo rate reached a level of 2.33 on March 19, 2008. Recall that on March 17, 2008 J. P. Morgan offered to purchase Bear Stearns for a price of $\$ 2$ per share, which allowed Bear Stearns to avoid filing bankruptcy. Thus, the premium of the tax-exempt rate over the taxable rate was very likely due to the perceived increase in systemic credit risk in the debt markets, or equivalently, the concurrent flight-to-quality that occurred in the Treasury markets. A key advantage of the empirical approach we adopt in this paper is that it allows us to identify the marginal tax rate separately from the credit and/or illiquidity spread incorporated into the tax-exempt curve.

\subsection{The Municipal Swap Data}

We obtain midmarket rates for 1-, 2-, 3-, 4-, 5-, 7-, 10-, 12-, 15-, and 20-year percentageof-Libor municipal swaps from the Bloomberg system for the same dates as described above. Recall that these municipal swap rates are quoted as percentages. ${ }^{7}$

Table 1 provides summary statistics for these municipal swap rates. Figure 2 plots the average values of the municipal swap rates during the sample period. As shown, the average percentage swap rate is not monotonic in the maturity of the swap. The average percentage is 76.06 for the 1-year swap, declines to 74.48 for the

${ }^{6}$ Based on intraday Bloomberg quotations on September 29, 2008 when the Dow Jones Industrial Index declined by over 777 points.

${ }^{7}$ We do not include the 25- and 30-year maturities in the study since data for these swaps are not available for much of the sample period. 
4-year swap, and then increases to a maximum of 78.17 percent for the 20-year swap. Although the average percentage swap rates are not monotonic, we observe that there are many dates during the sample period when the percentage swap rates are either monotonically increasing or decreasing with swap maturity. Table 1 shows that there is considerable time series variation in the percentage swap rates. In particular, the standard deviation of the percentage swap rate ranges from 8.35 percent for the 1-year swap to 2.53 percent for the 20-year swap. Thus, longer-term percentage swap rates are significantly less volatile than are shorter-maturity percentage swap rates. This suggests the possibility that there could be a mean-reverting nature to the relation between tax-exempt and taxable rates.

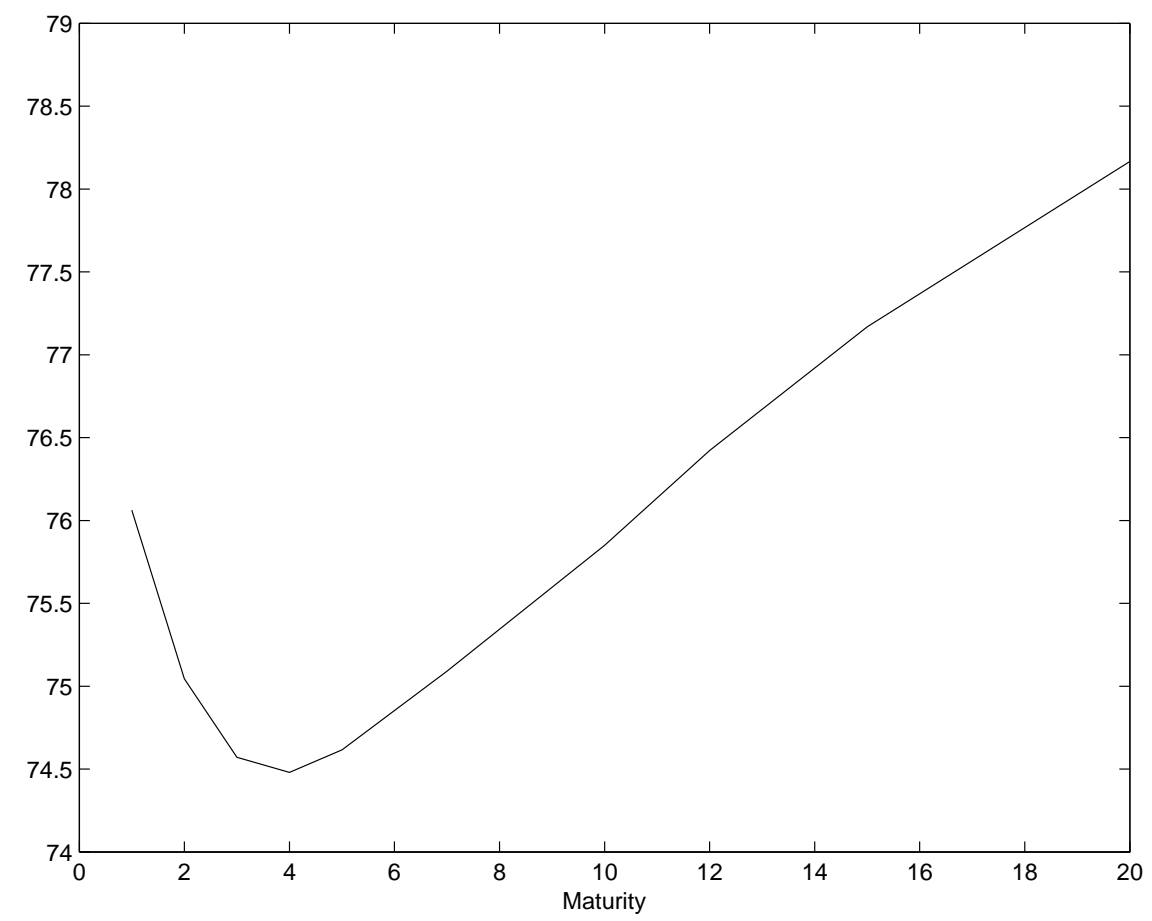

Figure 2. Average Municipal Swap Rates. This plot shows the average values of the municipal swap rates during the sample period. These rates are expressed as a percentage of Libor.

\subsection{Treasury Term Structure and Interest Rate Swap Data}

In the analysis later in the paper, we discount cash flows using a riskless discount function bootstrapped from the Treasury yield curve. Specifically, we obtain constant maturity Treasury (CMT) rates from the Federal Reserve Board's historical H.15 data for 1-month, 3-month, 6-month, 1-year, 2-year, 3-year, 5-year, 7-year, 10-year, and 20- 
year maturities for the same dates as for the other time series. Using a standard cubic spline algorithm, we then solve for the riskless discount function $D_{t}(T)$ for weekly maturities up to 20 years for each date during the sample period. This algorithm in described in Longstaff, Mithal, and Neis (2005).

We also use midmarket data for conventional fixed-for-floating Libor interest rate swaps in the analysis. In particular, we collect midmarket rates for 1-, 2-, 3-, 4-, 5-, $7-, 10-, 12-, 15-$, and 20-year interest rate swaps from the Bloomberg system for the same dates as above. ${ }^{8}$

\section{THE MARGINAL TAX RATE MODEL}

In this section, we describe the approach used to model the marginal tax rate incorporated into the tax-exempt MSI rate. In doing this, it is important to allow for the possibility that the MSI rate may include a spread reflecting the higher credit risk of even highly-rated VRDOs relative to the riskless rate. Furthermore, our approach will also address the possibility that VRDO yields may include a component reflecting the lower liquidity of municipal securities relative to that of Treasury securities.

Let $M_{t}$ denote the tax-exempt one-week MSI rate. This rate can be expressed in the following way,

$$
M_{t}=\left(r_{t}+\lambda_{t}\right)\left(1-\tau_{t}\right),
$$

where $r_{t}$ is the riskless pretax interest rate. In this expression $\lambda_{t}$ is a pretax spread reflecting either the credit risk of the tax-exempt index, the illiquidity of the VRDOs incorporated in the index, or some combination of both. The term $\tau_{t}$ designates the marginal tax rate of the marginal investor in VRDOs. We also assume that the taxable one-month Libor rate $L_{t}$ can be expressed as

$$
L_{t}=r_{t}+\mu_{t},
$$

\footnotetext{
${ }^{8}$ These swap data represent the market rate for exchanging fixed coupons for threemonth Libor. In contrast, the Libor leg of the municipal swaps involves one-month Libor. During the sample period, however, the midmarket value of the basis swap for exchanging one-month Libor for three-month Libor is within a fraction of a basis point of zero. Thus, there is little or no loss of accuracy in treating the Libor legs of the municipal and conventional interest rate swaps as if they were on the same underlying Libor index.
} 
where $\mu_{t}$ also represents a credit/liquidity spread incorporated into the Libor rate.

We will make the simplifying assumption that $r_{t}, \lambda_{t}, \mu_{t}$, and $\tau_{t}$ all follow independent processes. This assumption has little effect on the results and could easily be relaxed. By making this assumption, however, we avoid the need to specify the dynamics of the riskless rate $r_{t}$ and the Libor credit/liquidity spread $\mu_{t}$.

The dynamics of the VRDO credit/liquidity spread $\lambda_{t}$ are given by

$$
\begin{aligned}
& d \lambda_{t}=\left(a-b \lambda_{t}\right) d t+c d Z_{\lambda t} \\
& d \lambda_{t}=\left(\hat{a}-\hat{b} \lambda_{t}\right) d t+c d Z_{\lambda t}
\end{aligned}
$$

under the risk-neutral $Q$ measure and the actual $P$ measure, respectively. Thus, we allow both of the constant parameters in the drift of the above processes to differ between the risk-neutral and actual measures. This simple but general specification has the advantage of allowing the market price of risk for $\lambda_{t}$ to be time varying. The process $Z_{\lambda t}$ is a standard Brownian motion. These dynamics allow the credit/liquidity spread to be mean reverting and to take on negative values. This latter feature is important since it is at least theoretically possible that under some extreme scenarios, the liquidity of the highest-rated municipal securities might equal or even exceed that of Treasury securities; these dynamics allow us to address this possibility.

Similarly, the dynamics of the marginal tax rate $\tau_{t}$ are assumed to follow,

$$
\begin{aligned}
& d \tau_{t}=\left(\alpha-\beta \tau_{t}\right) d t+\sigma d Z_{\tau t}, \\
& d \tau_{t}=\left(\hat{\alpha}-\hat{\beta} \tau_{t}\right) d t+\sigma d Z_{\tau t},
\end{aligned}
$$

under the $Q$ and $P$ measures, respectively. These dynamics again imply that $\tau_{t}$ follows a mean-reverting Gaussian or Ornstein-Uhlenbeck process. The motivation for allowing for mean reversion in these dynamics comes from the observation that the volatility of longer-term municipal swap rates is a decreasing function of maturity. The motivation for assuming Gaussian dynamics, which can allow $\tau_{t}$ to take on negative values, is to allow for the fact that an investor's marginal tax rate can actually be slightly negative under some extreme circumstances.

Turning now to the valuation of percentage-of-Libor municipal swap contracts, observe that all of the cash flows associated with the swap will typically be taxable; 
the tax-exempt status of the VRDOs underlying the MSI rate does not transfer to swaps even though these swaps have cash flows tied to the tax-exempt rate. Thus, in present valuing swap cash flows, it is appropriate to use the usual pretax riskless discount function applied in standard valuation problems in Finance.

Let $D_{t}(T)$ denote the value at time $t$ of a riskless zero-coupon bond with a maturity of $T$ years. ${ }^{9}$ Under the risk-neutral pricing measure, the present value of the floating MSI leg of a percentage-of-Libor municipal swap contract with maturity $T$ can be expressed formally as

$$
E_{Q}\left[\int_{0}^{T} \exp \left(-\int_{0}^{s} r_{t+u} d u\right)\left(r_{t+s}+\lambda_{t+s}\right)\left(1-\tau_{t+s}\right) d s\right] .
$$

Similarly, the present value of the Libor leg of this swap can be expressed as

$$
P_{t}(T) E_{Q}\left[\int_{0}^{T} \exp \left(-\int_{0}^{s} r_{t+u} d u\right)\left(r_{t+s}+\mu_{t+s}\right) d s\right]
$$

where $P_{t}(T)$ designates the fraction of Libor paid in this percentage-of-Libor swap.

This latter expression depends on the Libor credit/liquidity spread $\mu_{t}$. This spread, however, can be substituted out of the model by noting that in a standard interest rate swap, the present value of receiving 100 percent of Libor is just the present value of receiving the current market swap rate which we designate $S_{t}(T)$. Specifically, the present value of the Libor leg in a standard interest rate swap

$$
E_{Q}\left[\int_{0}^{T} \exp \left(-\int_{0}^{s} r_{t+u} d u\right)\left(r_{t+s}+\mu_{t+s}\right) d s\right],
$$

equals the present value of receiving an annuity of $S_{t}(T)$ from the fixed leg of the swap,

$$
S_{t}(T) E_{Q}\left[\int_{0}^{T} \exp \left(-\int_{0}^{s} r_{t+u} d u\right) d s\right]
$$

\footnotetext{
${ }^{9}$ Throughout this section, we assume that swap cash flows are paid continuously. In actuality, however, cash flows from swaps are paid discretely. This assumption greatly simplifies the exposition and has virtually no effect on the empirical results.
} 
which can also be expressed as

$$
S_{t}(T) \int_{0}^{T} D_{t}(s) d s
$$

Combining these results implies that the present value of the percentage-of-Libor leg of the municipal swap is given by

$$
S_{t}(T) P_{t}(T) \int_{0}^{T} D_{t}(s) d s .
$$

To solve for the percentage swap rate $P_{t}(T)$, we observe that,

$$
-D_{t}^{\prime}(s)=E_{Q}\left[\exp \left(-\int_{0}^{s} r_{t+u} d u\right) r_{t+s}\right] .
$$

Setting the present values in Equations (7) and (12) equal to each other and solving for $P_{t}(T)$ gives

$$
P_{t}(T)=\frac{-\int_{0}^{T} D_{t}^{\prime}(s) E_{Q}\left[1-\tau_{t+s}\right] d s+\int_{0}^{T} D(s) E_{Q}\left[\lambda_{t+s}\right] E_{t}\left[1-\tau_{t+s}\right] d s}{S_{t}(T) \int_{0}^{T} D(s) d s} .
$$

From Equations (3) and (5),

$$
\begin{aligned}
E_{Q}\left[1-\tau_{t+s}\right] & =1-\tau_{t} e^{-\beta s}-\frac{\alpha}{\beta}\left(1-e^{-\beta s}\right), \\
E_{Q}\left[\lambda_{t+s}\right] & =\lambda_{t} e^{-b s}+\frac{a}{b}\left(1-e^{-b s}\right) .
\end{aligned}
$$

The Appendix shows that substituting these expressions into Equation (14) and evaluating the integrals gives the following solution for $P_{t}(T)$

$$
P_{t}(T)=\phi_{t}(T)+\psi_{t}(T) \tau_{t}+\xi_{t}(T) \lambda_{t}+\zeta_{t}(T) \lambda_{t} \tau_{t},
$$


where

$$
\begin{aligned}
\phi_{t}(T) & =\frac{1-\left(1-\frac{\alpha}{\beta}\left(1-e^{-\beta T}\right)\right) D_{t}(T)+\frac{a(\beta-\alpha)}{b \beta} A_{t}(0, T)}{S_{t}(T) A_{t}(0, T)} \\
& +\frac{\frac{a(\alpha-\beta)}{b \beta} A_{t}(b, T)+\frac{\alpha(a-b \beta)}{b \beta} A_{t}(\beta, T)-\frac{a \alpha}{b \beta} A_{t}(b+\beta, T)}{S_{t}(T) A_{t}(0, T)} \\
\psi_{t}(T) & =\frac{-1+e^{-\beta T} D_{t}(T)+\left(\beta-\frac{a}{b}\right) A_{t}(\beta, T)+\frac{a}{b} A_{t}(b+\beta, T)}{S_{t}(T) A_{t}(0, T)} \\
\xi_{t}(T) & =\frac{\left(1-\frac{\alpha}{\beta}\right) A_{t}(b, T)+\frac{\alpha}{\beta} A_{t}(b+\beta, T)}{S_{t}(T) A_{t}(0, T)} \\
\zeta_{t}(T) & =\frac{-A_{t}(b+\beta, T)}{S_{t}(T) A_{t}(0, T)}
\end{aligned}
$$

and where

$$
A_{t}(u, T)=\int_{0}^{T} D_{t}(s) e^{-u s} d s
$$

From this equation, we see that given the discount function $D_{t}(s)$, the percentage swap rate $P_{t}(T)$ is simply a bilinear function of $\tau_{t}$ and $\lambda_{t}$. Thus, since the MSI rate is also an explicit function of $\tau_{t}$ and $\lambda_{t}$, we can solve for $\tau_{t}$ and $\lambda_{t}$ directly from the MSI and percentage swap rates.

\section{MAXIMUM LIKELIHOOD ESTIMATION}

To estimate the model, we use a maximum likelihood approach similar to that often used in estimating term structure models. Important examples of the applications of this methodology to term structure estimation include Duffie and Singleton (1997), Duffee (2002), Liu, Longstaff, and Mandell (2006).

Paralleling Duffie and Singleton (1997), we assume that the MSI rate and the 10-year percentage swap rates are measured without error. Thus, given $r_{t}$ and the 
discount function $D_{t}(T)$, and conditional on the parameter vector $\theta$, we can invert Equations (1) and (17) to solve explicitly for $\lambda_{t}$ and $\tau_{t}$. In fact, given the simple functional form of Equation (1) and the bilinear form of Equation (17), the value of $\tau_{t}$ is given from a simple quadratic equation. Specifically, the solutions for $\lambda_{t}$ and $\tau_{t}$ are given by

$$
\begin{aligned}
\lambda_{t} & =\frac{M_{t}}{\left(1-\tau_{t}\right)}-r_{t}, \\
\tau_{t} & =\frac{-\kappa_{t}(T)-\sqrt{\kappa_{t}(T)^{2}-4 \nu_{t}(T) \chi_{t}(T)}}{2 \nu_{t}(T)},
\end{aligned}
$$

where

$$
\begin{aligned}
& \nu_{t}(T)=-\psi_{t}(T)+\zeta_{t}(T) r_{t} \\
& \kappa_{t}(T)=P_{t}(10)-\phi_{t}(T)+\psi_{t}(T)+\xi_{t}(T) r_{t}+\zeta_{t}(T) M_{t}-\zeta_{t}(T) r_{t} \\
& \chi_{t}(T)=-P_{t}(10)+\phi_{t}(T)+\xi_{t}(T) M_{t}-\xi_{t}(T) r_{t} .
\end{aligned}
$$

Thus, $\lambda_{t}$ and $\tau_{t}$ can be expressed as explicit functions of $M_{t}$ and $P_{t}(10)$. Let $J_{t}$ denote the Jacobian of the mapping from $M_{t}$ and $P_{t}(10)$ to $\lambda_{t}$ and $\tau_{t}$.

From the values of $\lambda_{t}, \tau_{t}$ and the parameter vector $\theta$, we can now solve for the percentage swap rate implied by the model for any maturity. Let $\epsilon_{t}$ denote the time- $t$ vector of differences between the market and model values of $P_{t}(T)$ implied by the values of $\tau_{t}, \lambda_{t}$, and $\theta$ for the 1-, 2-, 3-, 4-, 5-, 7-, 12-, 15-, and 20-year municipal swaps. Under the assumption that $\epsilon_{t}$ is conditionally multivariate normal with mean vector zero and a diagonal covariance matrix $\Sigma$ with diagonal values $v_{1}^{2}, v_{2}^{2}, v_{3}^{2}, v_{4}^{2}, v_{5}^{2}$, $v_{7}^{2}, v_{12}^{2}, v_{15}^{2}$, and $v_{20}^{2}$ (where the subscripts denote the maturities of the corresponding municipal swaps), the $\log$ likelihood function for $M_{t+\Delta t}, P_{t+\Delta t}$, and $\epsilon_{t+\Delta t}$ conditional on $M_{t}, P_{t}(10)$, and the term structure information is

$$
\begin{gathered}
L L K_{t}=-\frac{11}{2} \ln (2 \pi)+\ln \left|J_{t+\Delta t}\right|-\frac{1}{2} \ln |\Sigma|-\frac{1}{2} \epsilon_{t+\Delta t}^{\prime} \Sigma^{-1} \epsilon_{t+\Delta t} \\
-\frac{1}{2} \ln \left(\frac{\sigma^{2}\left(1-e^{-2 \hat{\beta} \Delta t}\right)}{2 \hat{\beta}}\right)-\left(\frac{\hat{\beta}\left(\tau_{t+\Delta t}-\tau_{t} e^{-\hat{\beta} \Delta t}-\frac{\hat{\alpha}}{\hat{\beta}}\left(1-e^{-\hat{\beta} \Delta t}\right)\right)^{2}}{\sigma^{2}\left(1-e^{-2 \hat{\beta} \Delta t}\right)}\right)
\end{gathered}
$$




$$
-\frac{1}{2} \ln \left(\frac{c^{2}\left(1-e^{-2 \hat{b} \Delta t}\right)}{2 \hat{b}}\right)-\left(\frac{\hat{b}\left(\lambda_{t+\Delta t}-\lambda_{t} e^{-\hat{b} \Delta t}-\frac{\hat{a}}{\hat{b}}\left(1-e^{-\hat{b} \Delta t}\right)\right)^{2}}{c^{2}\left(1-e^{-2 \hat{b} \Delta t}\right)}\right) .
$$

The total log likelihood function is then given by summing $L L K_{t}$ over all of the weekly observations.

We maximize the log likelihood function over the 19-dimensional parameter vector $\theta$ with a standard quasi-Newton algorithm using a finite-difference gradient. As a robustness check that the algorithm achieves the global maximum, we repeat the estimation using a variety of different starting values for the parameter vector. Table 2 reports the maximum likelihood estimates of the parameters along with their asymptotic standard errors.

\section{THE EMPIRICAL RESULTS}

In this section, we focus first on the estimated municipal default/liquidity spread $\lambda_{t}$ and its risk premium. We then report the results for the estimated marginal tax rate $\tau_{t}$ and examine the implications for asset prices and financial markets. Finally, we address the issue of the efficiency of prices in the municipal swap market and the relative valuation of municipal swap contracts.

\subsection{The Credit/Liquidity Spread}

Table 3 provide summary statistics about the estimated values of the municipal credit/ liquidity spread $\lambda_{t}$. Figure 3 plots the time series of the estimated values of $\lambda_{t}$. As shown, there is a substantial credit/liquidity spread incorporated into the MSI rate. The average value of $\lambda_{t}$ during the sample period is 106.0 basis points. The value of $\lambda_{t}$, however, has varied significantly throughout the sample period, ranging from -85.0 basis points to 423.8 basis points. The standard deviation of $\lambda_{t}$ is 70.8 basis points.

Figure 3 shows that the value of $\lambda_{t}$ is generally positive. Of the 360 weeks in the sample period, the estimated value of $\lambda_{t}$ is positive for 351 weeks, or equivalently, for 97.5 percent of the sample. For most of the first two-thirds of the sample period, the credit/liquidity spread hovers between roughly 25 basis points to 100 basis points. Beginning about mid 2006, however, the value of $\lambda_{t}$ starts to increase, often reaching levels in excess of 200 basis points or more as the subprime crisis of 2007 unfolded. The largest negative value of $\lambda_{t}$ occurs on February 13, 2008 which was close to the height of the period during which auction failures in the auction-rate security markets became widespread. Thus, the quality of market data in the closely-related VRDO market could easily have been adversely impacted during this period. 


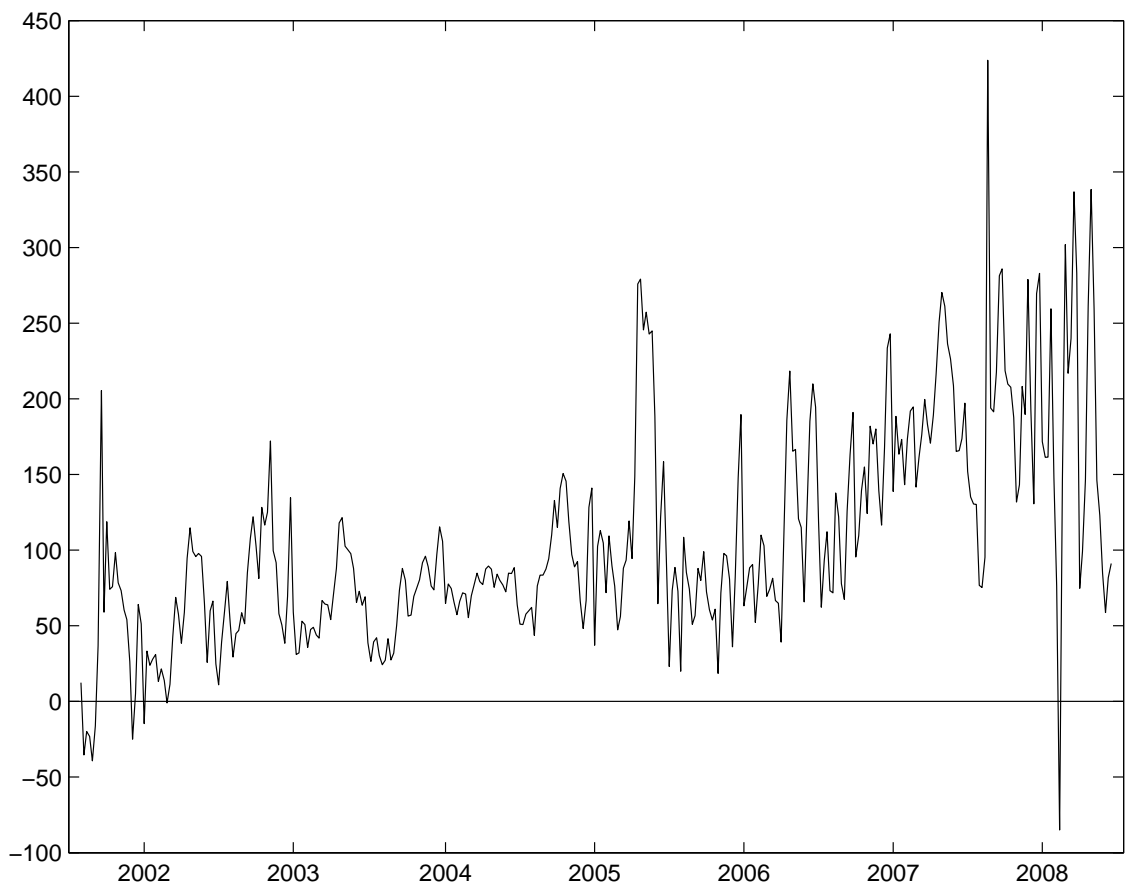

Figure 3. The Credit/Liquidity Spread. This plot shows the estimated credit/liquidity spread $\lambda_{t}$ during the sample period.

\subsection{The Credit/Liquidity Risk Premium}

The maximum likelihood estimates of $\hat{a}$ and $\hat{b}$ in Table 2 imply that the long-run mean of $\lambda_{t}$ under the actual measure is 104.6 basis points. This is in close agreement with the average value of $\lambda_{t}$ reported in Table 3 . In contrast, the maximum likelihood estimates of $a$ and $b$ imply that the long-run mean of $\lambda_{t}$ under the risk-neutral measure is 150.0 basis points. Thus, there is clearly a significant risk premium associated with $\lambda_{t}$; the market prices securities as if the long-run value of $\lambda_{t}$ were about 45 basis points higher than its actual long-run value.

To put these results into asset-pricing terms, Table 4 reports summary statistics for the difference between the expected value of $\lambda_{t}$ under the risk-neutral and actual measures, $E_{Q}\left[\lambda_{T}\right]-E_{P}\left[\lambda_{T}\right]$. Recall that the expected value of $\lambda_{T}$ under the riskneutral measure $Q$ is just the no-arbitrage price for a futures or forward contract that settles to $\lambda_{T}$. Thus, these differences capture the spread between the forward value of $\lambda_{T}$ and the expected spot value of $\lambda_{T}$. As such, the spread directly measures the risk premium that hedger would be willing to pay to lock in the future value of $\lambda_{T}$ via a futures or forward contract. 
As shown, the average risk premium is an increasing function of the horizon. The average risk premium is 28.8 basis points for the one-year horizon, 39.2 basis points for a two-year horizon, and 45.4 basis points for a ten-year horizon. Table 4 also shows that there is considerable variation in the risk premium, at least for some of the shorter horizons. For longer horizons, the risk premium is less volatile which is not surprising given the rapid estimated speeds of mean reversion for $\lambda_{t}$ under both measures.

\subsection{The Marginal Tax Rate}

Table 3 also reports summary statistics for the estimated marginal tax rate $\tau_{t}$. Figure 4 plots the time series of the estimated values of $\tau_{t}$. The average value of $\tau_{t}$ during the sample period is 41.57 percent. This average value is somewhat higher than the highest Federal income tax rate during the sample period. Specifically, the highest Federal income tax rate was 39.1 percent during 2001, 38.6 percent during 2002, and 35.0 percent during 2003-2008.

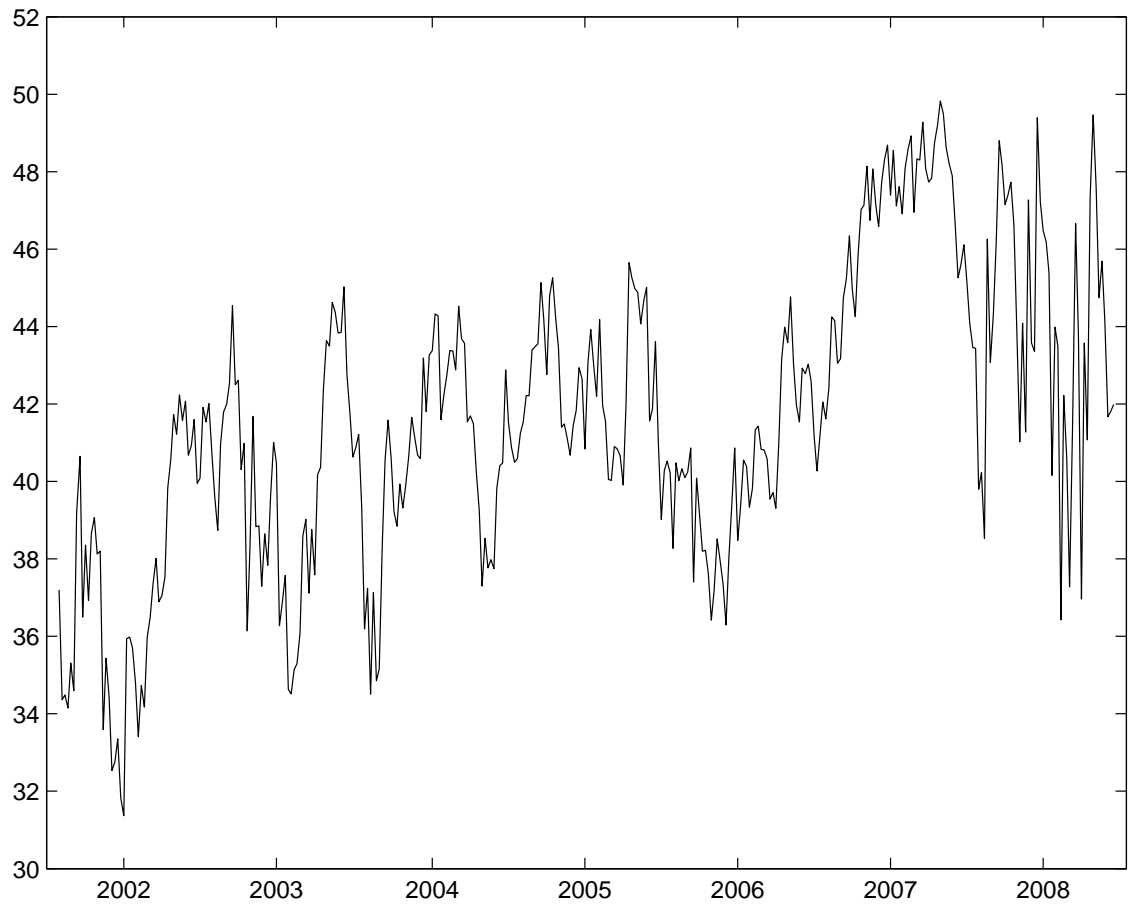

Figure 4. The Marginal Tax Rate. This plot shows the estimated marginal tax rate $\tau_{t}$ during the sample period.

It is important to recognize, however, that the MSI rate is a average of yields on VRDOs from a broad collection of municipal issuers from virtually every state. 
Thus, the marginal tax rate incorporated into the index may in fact reflect Federal, state, and possibly county, city, or other local income taxes as well. For example, a resident of New York City faces a maximum Federal income tax rate of 35 percent, a maximum New York State income tax rate of 8.14 percent, and a maximum New York City income tax rate of 4.00 percent. The overall maximum tax rate, however, is not just the sum of these rates since state and local income taxes may be deductible from Federal income taxes (subject to limitations such as those imposed by the alternative minimum tax; see Feenberg and Poterba (2004)). Assuming that the New York State and New York City income taxes were fully deductible, the maximum income tax rate faced by a New York City taxpayer would be $35.00+0.65 \times(8.14+4.00)=42.89$ percent. Similarly, California taxpayers face a maximum state income tax rate of 10.3 percent. Again assuming full deductibility, this implies that the maximum income tax rate faced by a California taxpayer would be $35.00+0.65 \times 10.3=41.695$ percent. These maximum tax rates closely approximate the average value of $\tau_{t}$ during the sample period.

The estimated value of $\tau_{t}$ varies throughout the sample period. During the first two-thirds of the sample period, $\tau_{t}$ hovers around 40 percent. During the early part of $2007, \tau_{t}$ begins to increase and then ranges between 40 and 50 percent for the rest of the sample period. The marginal tax rate is clearly much more volatile during the 2007-2008 period. The maximum value of $\tau_{t}$ occurs on March 21, 2007. The minimum value of $\tau_{t}$ occurs on March 5, 2008, coinciding with the period during which Bear Stearns was in imminent danger of going bankrupt.

\subsection{The Tax Risk Premium}

As with the credit/liquidity spread, we can also examine whether there is a tax risk premium embedded into security prices to compensate investors for being exposed to changes in the marginal tax rate. Turning again to Table 2, we see that the maximum likelihood estimates of $\hat{\alpha}$ and $\hat{\beta}$ imply that the long-run mean of $\tau_{t}$ under the actual measure is 41.69 percent which is very close to the average value reported in Table 3 .

Surprisingly, however, the maximum likelihood estimates of $\alpha$ and $\beta$ imply that the long-run mean of $\tau_{t}$ under the risk-neutral pricing measure is only 29.37 percent. Thus, these results indicate that there is a tax risk premium. This tax risk premium, however, actually has a negative sign. This suggests that investor would require a lower expected return to hold a security with cash flows that are sensitive to changes in the tax rate. In other words, investors view tax risk as being contracyclical.

To make this latter result more intuitive, let us consider the case of a taxable investor who holds a Treasury bond. For concreteness, assume that the bond has a market value of 100 and a fixed coupon of 6 percent. From an aftertax perspective, the actual cash flow received by the investor each year is $6\left(1-\tau_{t}\right)$. Since Federal marginal tax rates are progressive, this means that the investor's tax rate $\tau_{t}$ generally declines 
when his income decreases, and vice versa (we are abstracting from the discreteness of the Federal income tax schedule). Thus, the aftertax cash flows received from the Treasury bond increase when the investor's income and marginal tax rate decline, and vice versa. Thus, the aftertax cash flows from the Treasury bond have almost a perfect negative correlation with the investor's income, which, in turn, maps into a strong negative consumption beta. Thus, in the same way that, for example, gold mining stocks have negative market betas and, therefore, lower required expected returns, Treasury bonds should have lower yields or expected returns because of their negative consumption betas.

To illustrate the size of the risk premium, Table 4 also reports summary statistics for the difference between the expected values of $\tau_{T}$ under the $Q$ and $P$ measures for various values of $T$. As shown, the average difference between the forward and expected values of $\tau_{T}$ ranges from about -0.017 for a one-year horizon, to more than -0.093 for horizons of ten years or more. The table also shows that there is significant time variation in the tax risk premium. For example, the tax risk premium for the one-year horizon ranges from -0.106 to 0.054 . Thus, the tax premium can sometimes take on positive values. For horizons of three years or more, the tax risk premium is always negative throughout the sample period.

\subsection{What Drives the Marginal Tax Rate?}

To explore the nature of the marginal tax rate in more detail, we regress changes in the estimated marginal tax rate on a number of measures potentially affecting the taxable income of the marginal municipal bond participant. In doing this, we first compute changes in the marginal tax rate over a monthly horizon (rather than over a weekly horizon as in the previous analysis). Specifically, we calculate the monthly change in $\tau_{t}$ using the first estimated value of $\tau_{t}$ for each month.

As explanatory variables, we use a variety of measures. First, we include the monthly return on the S\&P 500 index (omitting dividends). Second, we use the monthly return on a broad portfolio of Treasury bonds with maturities ranging from 2 to 30 years. The data for this return series is reported by Bloomberg. Third, we use the monthly return on a broad index of commodity prices, also calculated and reported by Bloomberg. These three measures attempt to proxy for the components of the marginal municipal bondholder's income that may be financial-market-value based. The final measure is the monthly change in per capita personal income reported by the Bureau of Economic Analysis.

Table 5 reports the results from this regression. As shown, changes in the marginal tax rate are significantly and positively related to stock market returns. Similarly, changes in the marginal tax rate are highly positively related to returns on Treasury bonds; the $t$-statistic for the Treasury bond returns is 3.74 . These results strongly support the hypothesis that the marginal tax rate is procyclical, and therefore, that 
cash flows that are multiplied by $\left(1-\tau_{t}\right)$ are countercyclical. These results also support the interpretation of the negative risk premium embedded in long-term municipal swap rates as a premium for the contracyclical behavior of aftertax fixed-income cash flows. In addition, the relation between the marginal tax rate and the financial markets provides interesting insights into the nature of the marginal investor. ${ }^{10}$

\subsection{The Relative Valuation of Municipal Swaps}

Since only the short-term tax-exempt rate $M_{t}$ and the 10-year municipal swap percentages $P_{t}(10)$ are fitted exactly, the other municipal swap percentages implied by the model will typically not match the corresponding market values exactly. To examine whether there are systematic differences between model and market values, we report summary statistics for these differences (which are the $\epsilon_{t}$ terms described in the previous section). Table 6 reports these summary statistics.

As shown, the mean pricing errors range from a minimum of -0.923 for the 15 -year municipal swap contract to a maximum of 2.607 for the 1-year contract. To test for statistical significance, we calculate the $t$-statistics for the mean where the standard deviation of each mean is adjusted for the serial correlation of the pricing errors. In general, these mean values are not significant. The exceptions are the 1-year, 2-year, and 20-year contracts which are all significantly positive.

Although not significant on average, Table 6 also shows that many of the pricing errors display a substantial amount of serial correlation. For example, the first-order serial correlation coefficients for the 1-, 2-, 3-, 12-, and 15-year pricing errors are all in excess of 0.70. Since we do not have transaction cost estimates for trading these municipal swap contracts, we cannot evaluate whether the persistence in these pricing errors could be the basis for a trading strategy. Nevertheless, the results raise interesting issues about relative valuation in the municipal swap market.

\section{CONCLUSION}

This paper uses a unique new data set of municipal swap rates to identify both the marginal tax rate and the credit/liquidity spread embedded in one-week tax-exempt municipal yields. By inferring these values from the one-week rate, our approach has the important advantage of completely avoiding the complexities of the tax treatment of long-term municipal bonds which Green (1993) illustrates can be very formidable.

We find that the average marginal tax rate incorporated into the one-week MSI rate is 41.6 during the 2001-2008 sample period. This average corresponds closely to

${ }^{10}$ See Feenberg and Poterba (1991). 
the actual maximum marginal Federal, state, and local income tax rates faced by individuals in California and New York. Furthermore, the marginal tax rate incorporated into tax-exempt rates is strongly related to both Treasury bond and stock market returns.

Most surprisingly, we find market prices imply a negative risk premium for bearing the risk of time varying marginal tax rates. This result, however, is fully consistent with the contracyclical behavior of aftertax cash flows. This follows simply from the fact that the marginal tax rate is higher in good states of the economy and vice versa. Thus, aftertax fixed-income cash flows, which are multiplied by $\left(1-\tau_{t}\right)$, are negatively correlated with the state of the economy. Thus, aftertax cash flows essentially have negative consumption betas, and therefore, negative risk premia.

In summary, our results indicate that the marginal tax rate is actually much higher than has been generally documented in the literature. The reason for the difference is that previous work has attempted to infer marginal tax rate from longerterm municipal bonds. Green (1993) offers a potential explanation for the muni-bond puzzle by showing how the simple comparison of longer-term municipal bond yields to corresponding taxable rate is problematic because of their asymmetric tax treatment. Our results complement those of Green by suggesting that an additional explanation for the muni-bond puzzle may be the existence of a significant negative tax risk premium embedded in municipal bond yields. 


\section{APPENDIX}

After multiplying through, the numerator in Equation (14) can be expressed as the sum

$$
\begin{aligned}
& -\int_{0}^{T} D_{t}^{\prime}(s) d s \\
& +\int_{0}^{T} D_{t}^{\prime}(s)\left(\left(\tau_{t}-\frac{\alpha}{\beta}\right) e^{-\beta s}+\frac{\alpha}{\beta}\right) d s \\
& +\int_{0}^{T} D_{t}(s)\left(\left(\lambda_{t}-\frac{a}{b}\right) e^{-b s}+\frac{a}{b}\right) d s \\
& -\int_{0}^{T} D_{t}(s)\left(\left(\lambda_{t}-\frac{a}{b}\right) e^{-b s}+\frac{a}{b}\right)\left(\left(\tau_{t}-\frac{\alpha}{\beta}\right) e^{-\beta s}+\frac{\alpha}{\beta}\right) d s .
\end{aligned}
$$

The integral in the first line of Equation (A1) reduces to $1-D_{t}(T)$. The integral in the second line reduces to

$$
\left(\tau_{t}-\frac{\alpha}{\beta}\right)\left[e^{-\beta T} D_{t}(T)-1+\beta A_{t}(\beta, T)\right]+\frac{\alpha}{\beta}\left(D_{t}(T)-1\right),
$$

after an integration by parts. The integral in the third line reduces to

$$
\left(\lambda_{t}-\frac{a}{b}\right) A_{t}(b, T)+\frac{a}{b} A_{t}(0, T) .
$$

The integral in the fourth line reduces to

$$
\begin{aligned}
& -\frac{a \alpha}{b \beta} A_{t}(0, T)-\frac{\alpha}{\beta}\left(\lambda_{t}-\frac{a}{b}\right) A_{t}(b, T) \\
& -\frac{a}{b}\left(\tau_{t}-\frac{\alpha}{\beta}\right) A_{t}(\beta, T)-\left(\lambda_{t}-\frac{a}{b}\right)\left(\tau_{t}-\frac{\alpha}{\beta}\right) A_{t}(b+\beta, T) .
\end{aligned}
$$


Substituting these expressions into the numerator of Equation (14) and collecting terms in $\lambda_{t}, \tau_{t}$, and $\lambda_{t} \tau_{t}$ gives the expression in Equation (17).

Turning now to the solutions for $\lambda_{t}$ and $\tau_{t}$ in Equations (23) and (24), observe that Equation (23) follows immediately from Equation (1). Substituting this expression of $\lambda_{t}$ into Equation (17) results in a quadratic equation for $\tau_{t}$. Taking the smallest positive root of the quadratic equation gives the solution for $\tau_{t}$ in Equation (24). 


\section{REFERENCES}

Ang, Andrew, Vineer Bhansali, and Yuhang Xing, 2008, Taxes on Tax-Exempt Bonds, Journal of Finance, forthcoming.

Ang, James, David Peterson, and Pamela Peterson, 1985, Marginal Tax Rates: Evidence from Nontaxable Corporate Bonds: A Note, Journal of Finance 40, 327-332.

Arak, M., and K. Guentner, 1983, The Market for Tax-Exempt Issues: Why are the Yields so High? National Tax Journal 36, 145-161.

Buser, Stephen A., and Patrick J. Hess, 1986, Empirical Determinants of the Relative Yields on Taxable and Tax-Exempt Securities, Journal of Financial Economics 17, 335-355.

Chalmers, John M. R., 1998, Default Risk Cannot Explain the Muni Puzzle: Evidence from Municipal Bonds that are Secured by U.S. Treasury Obligations, Review of Financial Studies 281-308.

Constantinides, George M., and Jonathan E. Ingersoll, Jr., 1982, Optimal Bond Trading with Personal Tax: Implications for Bond Prices and Estimated Tax Brackets and Yield Curves, Journal of Finance 37, 349-352.

Criscuolo, Anthony C., and Michael Faloon, 2007, Variable Rate Demand Obligations, Standish Mellon Asset Management.

Dammon, Robert M., and Richard C. Green, 1987, Tax Arbitrage and the Existence of Equilibrium Prices for Financial Assets, Journal of Finance 42, 1143-1166.

Dammon, Robert M., Chester S. Spatt, and Harold H. Zhang, 2004, Optimal Asset Location and Allocation with Taxable and Tax-Deferred Investing, Journal of Finance 59, 999-1037.

Downing, Chris and Frank Zhang, 2004, Trading Activity and Price Volatility in the Municipal Bond Market, Journal of Finance 59, 899-931.

Duffee, Gregory R., 1998, Idiosyncratic Variation in Treasury Bill Returns, Journal of Finance 51, 527-551.

Duffee, Gregory R., 2002, Term Premia and Interest Rate Forecasts in Affine Models, Journal of Finance 57, 405-443.

Duffie, Darrell, and Kenneth J. Singleton, 1997, An Econometric Model of the Term Structure of Interest Rate Swap Yields, Journal of Finance 52, 1287-1323. 
Dybvig, Philip H., and Stephen A. Ross, 1986, Tax Clienteles and Asset Pricing, Journal of Finance 41, 751-762.

Feenberg, Daniel, and James M. Poterba, 1991, Which Households Own Municipal Bonds? Evidence from Tax Returns, National Tax Journal 44, 93-103.

Feenberg, Daniel, and James M. Poterba, 2004, The Alternative Minimum Tax and Effective Marginal Tax Rates, National Tax Journal 57, 407-427.

Graham, John R., 2003, Taxes and Corporate Finance: A Review, Review of Financial Studies 1075-1129.

Green, Richard C., 1993, A Simple Model of the Taxable and Tax-Exempt Yield Curves, Review of Financial Studies 6, 233-264.

Green, Richard C., 2007, Issuers, Underwriter Syndicates, and Aftermarket Transparency, Journal of Finance 62 1529-1550.

Green, Richard C., Burton Hollifield, and Norman Schürhoff, 2007a, Financial Intermediation in Opaque Markets, Review of Financial Studies 20, 275-314.

Green, Richard C., Burton Hollifield, and Norman Schürhoff, 2007b, Dealer Intermediation and Price Behavior in the Aftermarket for New Bond Issues, Journal of Financial Economics 86, 643-682.

Green, Richard C., Dan Li, and Norman Schürhoff, 2007, Price Discovery in Illiquid Markets, Working paper, Carnegie-Mellon University.

Green, Richard C., and Bernt A. Oedegaard, 1997, Are There Tax Effects in the Relative Pricing of U.S. Government Bonds? Journal of Finance 52, 609-633.

Jordan, James V., 1984, Tax Effects in Term Structure Estimation, Journal of Finance 39, 393-406.

Kidwell, David S., and Charles A. Trzcinka, 1982, Municipal Bond Pricing and the New York City Fiscal Crisis, Journal of Finance 37, 1239-1246.

Kochin, Levis A., and Richard W. Parks, 1988, Was the Tax-Exempt Bond Market Inefficient or were Future Expected Tax Rates Negative? Journal of Finance 43, 913931.

Litzenberger, Robert H., and Jacques Rolfo, 1984, An International Study of Tax Effects on Government Bonds, Journal of Finance 39, 1-22.

Livingson, Miles, 1979, Bond Taxation and the Shape of the Yield-to-Maturity Curve, Journal of Finance 34, 189-196. 
Livingston, Miles, 1982, The Pricing of Municipal Bonds, Journal of Financial and Quantitative Analysis 17, 179-193.

Liu, Jun, Francis A. Longstaff, and Ravit E. Mandell, 2006, The Market Price of Risk in Interest Rate Swaps: The Roles of Default and Liquidity Risks, Journal of Business 79, 2337-2359.

Longstaff, Francis A., 2000, The Term Structure of Very Short Term Rates: New Evidence for the Expectations Hypothesis, Journal of Financial Economics 58, 397-415.

Longstaff, Francis A., 2004, The Flight-to-Liquidity Premium in U.S. Treasury Bond Prices, Journal of Business 77, 511-526.

Longstaff, Francis A., Sanjay Mithal, and Eric Neis, 2005, Corporate Yield Spreads: Default Risk or Liquidity? New Evidence from the Credit-Default Swap Market, Journal of Finance 60, 2213-2253.

McConnell, John, and Alessio Saretto, 2008, Auction Failures and the Market for Auction Rate Securities, Working paper, Purdue University.

Nanda, Vikram, and Rajdeep Singh, 2004, Bond Insurance: What is Special About Munis? Journal of Finance 59, 2253-2279.

Neis, Eric, 2006, Liquidity and Municipal Bonds, Working paper, UCLA.

Schaefer, Stephen M., 1982, Tax-Induced Clientele Effects in the Market for British Government Securities, Journal of Financial Economics 10, 121-159.

Skelton, Jeffrey L., 1983, Relative Risk in Municipal and Corporate Debt, Journal of Finance 38, 625-634.

Stock, Duane and Edward L. Schrems, 1984, Municipal Bond Demand Premiums and Bond Price Volatility: A Note, Journal of Finance 39, 535-539.

Sulzberge, Frank, and Andrew Flynn, 2008, Lessons From Tough Times: Understanding VRDO Failures, The Bond Buyer July 21.

Trzcinka, Charles, 1982, The Pricing of Tax-Exempt Bonds and the Miller Hypothesis, Journal of Finance 37, 907-923. 
Table 1

Summary Statistics for the Municipal Index and the Municipal Swaps. This tables report summary statistics for the indicated variables. The 1-week MSI rate is expressed as a percentage. The municipal swap rates are expressed as percentages of Libor. The sample consists of weekly (Wednesday) observations for the August 1, 2001 to June 18, 2008 period.

\begin{tabular}{|c|c|c|c|c|c|c|c|}
\hline Index & Mean & $\begin{array}{l}\text { Standard } \\
\text { Deviation }\end{array}$ & Minimum & Median & Maximum & $\begin{array}{r}\text { Serial } \\
\text { Correlation }\end{array}$ & $N$ \\
\hline 1-Week MSI Rate & 2.179 & 1.032 & 0.700 & 1.875 & 3.970 & 0.985 & 360 \\
\hline 1-Year Municipal Swap & 76.062 & 8.352 & 66.500 & 72.938 & 98.000 & 0.987 & 360 \\
\hline 2-Year Municipal Swap & 75.044 & 6.593 & 67.250 & 72.938 & 91.250 & 0.988 & 360 \\
\hline 3-Year Municipal Swap & 74.571 & 5.433 & 67.625 & 73.469 & 89.500 & 0.983 & 360 \\
\hline 4-Year Municipal Swap & 74.480 & 4.690 & 68.125 & 73.880 & 87.250 & 0.981 & 360 \\
\hline 5-Year Municipal Swap & 74.616 & 4.265 & 68.500 & 74.313 & 85.750 & 0.985 & 360 \\
\hline 7-Year Municipal Swap & 75.090 & 3.553 & 69.563 & 75.130 & 83.250 & 0.962 & 360 \\
\hline 10-Year Municipal Swap & 75.850 & 2.970 & 70.563 & 76.065 & 82.630 & 0.979 & 360 \\
\hline 12-Year Municipal Swap & 76.422 & 2.794 & 71.125 & 76.630 & 82.630 & 0.977 & 360 \\
\hline 15-Year Municipal Swap & 77.169 & 2.653 & 71.813 & 77.500 & 82.630 & 0.977 & 360 \\
\hline 20-Year Municipal Swap & 78.166 & 2.528 & 72.813 & 78.630 & 82.880 & 0.975 & 360 \\
\hline
\end{tabular}


Table 2

Maximum Likelihood Estimates of the Model Parameters. This table reports the maximum likelihood parameters of the model along with their asymptotic standard errors.

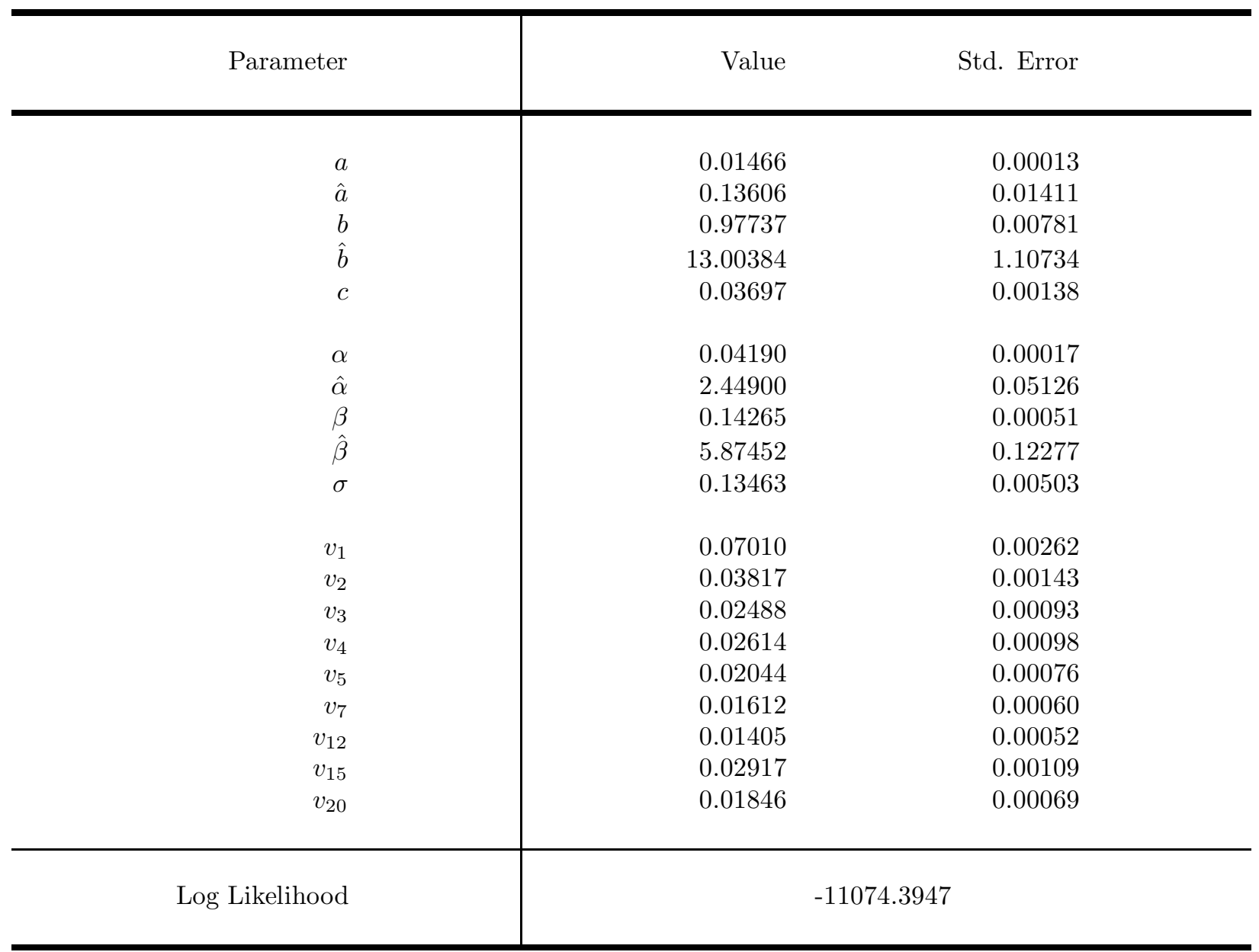


Table 3

Summary Statistics for the Credit/Liquidity Spread and the Marginal Tax Rate. This table reports summary statistics of the estimated credit/liquidity spread $\lambda_{t}$ and the marginal tax rate $\tau_{t}$.

\begin{tabular}{|c|c|c|c|c|c|c|c|}
\hline Variable & Mean & $\begin{array}{l}\text { Standard } \\
\text { Deviation }\end{array}$ & Minimum & Median & Maximum & $\begin{array}{r}\text { Serial } \\
\text { Correlation }\end{array}$ & $N$ \\
\hline$\lambda_{t}$ & 0.01060 & 0.00708 & -0.00850 & 0.00879 & 0.04238 & 0.765 & 360 \\
\hline$\tau_{t}$ & 0.41574 & 0.03784 & 0.31369 & 0.41489 & 0.49826 & 0.884 & 360 \\
\hline
\end{tabular}


Table 4

Risk Premia. This table reports the mean, minimum, and maximum values for the credit/liquidity and marginal tax rate risk premia for the indicated horizons (in years). The risk premium is defined as the difference between the forward value of the variable and its expected value, where the forward value represents the expected value of the variable under the risk-neutral measure.

\begin{tabular}{|c|c|c|c|c|c|c|c|}
\hline & & 1 & 2 & 3 & 5 & 10 & $\infty$ \\
\hline$\lambda_{t}$ Risk Premium & $\begin{array}{l}\text { Mean } \\
\text { Minimum } \\
\text { Maximum }\end{array}$ & $\begin{array}{r}0.00288 \\
-0.00430 \\
0.01484\end{array}$ & $\begin{array}{l}0.00392 \\
0.00121 \\
0.00842\end{array}$ & $\begin{array}{l}0.00430 \\
0.00329 \\
0.00600\end{array}$ & $\begin{array}{l}0.00451 \\
0.00436 \\
0.00475\end{array}$ & $\begin{array}{l}0.00454 \\
0.00454 \\
0.00454\end{array}$ & $\begin{array}{l}0.00454 \\
0.00454 \\
0.00454\end{array}$ \\
\hline$\tau_{t}$ Risk Premium & $\begin{array}{l}\text { Mean } \\
\text { Minimum } \\
\text { Maximum }\end{array}$ & $\begin{array}{r}-0.01736 \\
-0.10556 \\
0.05396\end{array}$ & $\begin{array}{r}-0.03143 \\
-0.10815 \\
0.03061\end{array}$ & $\begin{array}{r}-0.04362 \\
-0.11014 \\
0.01017\end{array}$ & $\begin{array}{l}-0.06336 \\
-0.11337 \\
-0.02292\end{array}$ & $\begin{array}{l}-0.09384 \\
-0.11835 \\
-0.07403\end{array}$ & $\begin{array}{l}-0.12314 \\
-0.12314 \\
-0.12314\end{array}$ \\
\hline
\end{tabular}


Table 5

Regression Results. This table reports the results from the regression of monthly changes in the estimated marginal tax rate on the indicated explanatory variables.

\begin{tabular}{l|rr}
\hline Explanatory Variable & Coefficient & $t$-Statistic \\
\hline Intercept & -0.00186 & -0.46 \\
S\&P 500 Return & 0.21955 & 2.20 \\
Treasury Bond Return & 0.93231 & 3.74 \\
Commodity Index Return & -0.08607 & -1.12 \\
Personal Income Growth & -0.00302 & -0.67 \\
\hline$R^{2}$ & & 0.1743 \\
Number of Observations & & 82 \\
\hline
\end{tabular}


Table 6

Municipal Swap Pricing Errors. This table reports summary statistics for the difference between the model-implied values of the indicated municipal swap rate and the market municipal swap rate. Municipal swap rates are expressed as percentages of Libor. Pricing errors for the 10-year swap are not reported since the 10-year swap rate is fitted exactly in the estimation algorithm.

\begin{tabular}{|c|c|c|c|c|}
\hline Swap Contract & Mean & $t$-Statistic & $\begin{array}{r}\text { Serial } \\
\text { Correlation }\end{array}$ & $N$ \\
\hline 1-Year Municipal Swap & 2.607 & 3.05 & 0.725 & 360 \\
\hline 2-Year Municipal Swap & 1.111 & 2.27 & 0.734 & 360 \\
\hline 3-Year Municipal Swap & -0.034 & -0.08 & 0.807 & 360 \\
\hline 4-Year Municipal Swap & -0.152 & -0.53 & 0.620 & 360 \\
\hline 5-Year Municipal Swap & 0.215 & 1.05 & 0.573 & 360 \\
\hline 7-Year Municipal Swap & 0.227 & 1.30 & 0.624 & 360 \\
\hline 10-Year Municipal Swap & - & - & - & - \\
\hline 12-Year Municipal Swap & -0.488 & -1.36 & 0.931 & 360 \\
\hline 15-Year Municipal Swap & -0.923 & -1.06 & 0.948 & 360 \\
\hline 20-Year Municipal Swap & 1.320 & 10.37 & 0.558 & 360 \\
\hline
\end{tabular}

